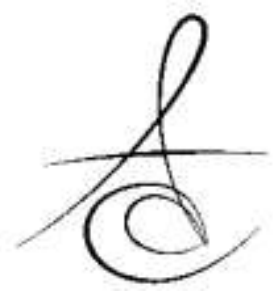

\title{
BUKKAL MUKOZADA İZLENEN FİBROLİPOM VAKASI VE LİTERATÜR DERLEMESİ
}

\section{A CASE OF FIBROLIPOMA IN THE BUCCAL MUCOSA AND REVIEW OF LITERATURE}

\author{
Arş. Gör. Muhsin Said KARATAŞ* \\ Arş. Gör. Basma AZNAD** \\ Prof. Dr. İlkay PEKER* \\ Arş. Gör. Öykü ÖZTÜRK ${ }^{* * *}$ \\ Prof. Dr. Cemile Özlem ÜçoK*
}

\author{
Makale Kodu/Article code: 3678 \\ Makale Gönderilme tarihi: 21.05.2018 \\ Kabul Tarihi: 13.07.2018 \\ DOI : $10.17567 /$ ataunidfd.443605
}

Muhsin Said Karataş: ORCID ID: 0000-0002-6373-2204

İlkay Peker: ORCID ID: 0000-0002-2888-2979

Basma Aznad: ORCID ID: 0000-0002-7927-6223

Öykü Öztürk: ORCID ID: 0000-0002-9970-1506

Cemile Özlem Üçok: ORCID ID: 0000-0003-4904-0591

\section{ÖZ}

Lipom oral kavitede nadir görülen bir neoplazmdır. Fibrolipom, histolojik bir lipom varyantıdır ve çoğunlukla bukkal mukozayı etkileyen, 40-60 yaşları arasında görülen, genellikle asemptomatik lezyonlardır. Rekurrens ve malign transformasyon olasılığı çok düşük olmakla birlikte, immüno-histokimyasal incelemede ki-67 gen ekspresyonu tespit edilen vakalarda uzun süreli takip önerilmektedir. Bu makalenin amacı, bukkal mukozada izlenen bir fibrolipom vakasının klinik ve histopatolojik bulgularını değerlendirmek ve konuyla ilgili literatür derlemesi sunmaktır. 74 yaşındaki erkek hastanın intraoral muayenesinde sağ bukkal mukozada, yaklaşık 1cm çapında, sapsız, yarı-sıkı kıvamda, ağrısız bir lezyon tespit edildi. Eksize edilen lezyonun histopatolojik incelemesi sonucunda, lezyona ki-67 gen ekspresyonu içeren fibrolipom tanısı konuldu. Hasta periyodik takibe alındı.

Anahtar Kelimeler: fibrolipoma, bukkal mukoza, eksizyonel biyopsi

\section{ABSTRACT}

Lipoma is a rare neoplasms of the oral cavity. Fibrolipoma is a histologic variant of lipoma and is usually asymptomatic lesions affecting buccal mucosa, seen between the ages of 40-60. Although the likelihood of recurrence and malign transformation is very low, long-term follow-up is recommended in cases where ki-67 gene expression in immunohistochemical examination. The aim of this article is to evaluate clinical and histopathological findings of a fibrolipoma case in the buccal mucosa and to present a review of relevant literature. In intraoral examination of a 74 years old male patient, a semi-firm and sessile painless lesion with a size of $1 \mathrm{~cm}$ is detected in the right buccal mucosa. The lesion has been surgically excised and diagnosed as fibrolipoma with ki-67 gene expression in the histopathological exam<ination. The patient has been periodically followed-up.

Keywords: fibrolipoma, buccal mucosa, excisional biopsy

* Gazi Üniversitesi Diş Hekimliği Fakültesi, Ağız, Diş ve Çene Radyolojisi A.D.

** Gazi Üniversitesi Diş Hekimliği Fakültesi, Oral Patoloji A.D.

*** Gazi Üniversitesi Diș Hekimliği Fakültesi, Ağız, Diș ve Çene Cerrahisi A. D.

Kaynakça Bilgisi: Karataş MS, Peker İ, Aznad B, Öztürk Ö, Üçok CÖ. Bukkal Mukozada İzlenen Fibrolipom Vakası ve Literatür Derlemesi. Atatürk Üniv Diş Hek Fak Derg 2020; 30: 130-137.

Citation Information: Karatas MS, Peker I, Aznad B, Ozturk O, Ucok CO. A Case of Fibrolipoma in The Buccal Mucosa and Review of Literature J Dent Fac Atatürk Uni 2020; 30: 130-137.

\section{GİRİş}

Lipomlar olgun yağ hücrelerinden kaynaklanan benign mezenşimal tümörlerdir. Oral benign tümörler içerisinde lipomların görülme sıklığı yaklaşık \% 1$4^{\prime}$ dür $^{1,2}$. Histolojik olarak lipomlar klasik lipomlar ve onun varyantları olan fibrolipom, iğsi lipom, intramuskuler lipom, anjiolipom, sialolipom, pleomorfik lipom, miksoid lipom ve atipik lipom olarak sınıflandırılabilir.

Lipomun etiyolojisi tam olarak bilinmemekle birlikte, travma sonucu meydana geldiği düşünülmek- tedir $^{1-4}$. Lipomlar genellikle yavaş büyüyen, iyi sınırlı, ağrısız lezyonlardır ${ }^{5-6}$. Oral lipom ve fibrolipom çeşitli anatomik bölgelerde görülmekle birlikte en sık bukkal mukozada izlenir ${ }^{2-11}$. İntraoral lipomlar büyük boyutlara ulaşırsa çiğneme ve konuşma fonksiyonlarında problemlere neden olabilir ${ }^{12}$. Lipomların tedavisi cerrahi eksizyondur.

Bu makalenin amacı, 74 yaşındaki bir erkek hastanın bukkal mukozasında izlenen fibrolipomun klinik ve histopatolojik özelliklerini değerlendirmek ve konuyla ilgili literatürü incelemektir. 


\section{VAKA RAPORU}

Kliniğimize diş taşlarının temizlenmesi için başvuran 74 yaşındaki erkek hastanın medikal anamnezinde hipertansiyon ve vertigo hastalığı olduğu öğrenildi. Hastanın antihipertansif (anjiotensin II antagonisti), psikostimülan, antitrombotik ve nootropik ilaç kullandığı öğrenildi. Dental anamnezde hasta sekiz yıldır kullandığı maksiller ve mandibuler hareketli bölümlü protezini üç ay önce değiştirdiğini, diş taşlarından şikayetçi olduğunu belirtti.

Hastanın ekstraoral muayenesinde herhangi bir patolojik bulgu izlenmedi. İntraoral muayenede maksiller ve mandibuler keser ve kanin dişlerin ağızda olduğu, sol maksiller kanin dişte kompozit dolgu restorasyonu ve her iki çenede diş taşları izlendi. Sağ bukkal mukozada, yaklaşık $1 \mathrm{~cm}$ çapında, mukozadan kabarık, sapsız, mukoza rengine yakın açık pembe renkte, yarı-sıkı kıvamda bir lezyon tespit edildi (Resim 1). Hastadan lezyonun ağrısız olduğu, üç ay önce hareketli bölümlü protezini yeniden yaptırdıktan sonra lezyonun farkına vardığı ve üç aydır lezyonu ısırdığı öğrenildi.

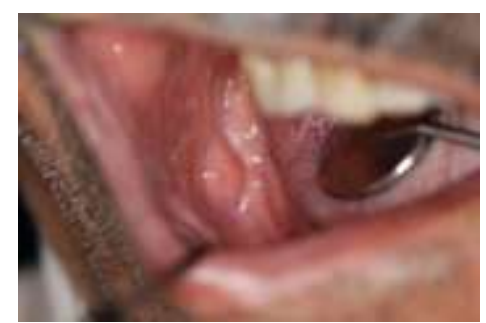

Resim 1. Sağ yanak mukozasındaki lezyonun intraoral fotoğrafı

Panoramik radyografi incelemesinde, sağ posterior bölgede, lezyonun boyutları ile uyumlu, yumuşak doku densitesinde radyoopasite izlendi. Lezyonun ön tanısında travmatik fibrom olabileceği düşünüldü (Resim 2).

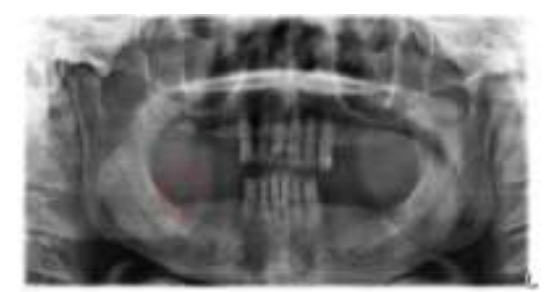

Resim 2. Panoramik radyografide sağ mandibular molar bölgede lezyon boyutları ile uyumlu olarak izlenen hafif radyoopasite

Lezyonun eksizyonu için hasta, Ağız, Diş ve Çene Cerrahisi Anabilim Dalına sevk edildi. Lezyonun eksizyonu sonrası yara yeri primer olarak kapatıldı ve hastaya, sütürlerin alınması için bir hafta sonrasına randevu verildi (Resim 3).

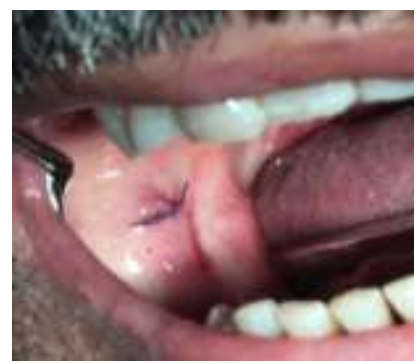

Resim 3. Lezyonun eksizyonu sonrası primer olarak kapatılan yara yeri

\section{Histopatolojik Değerlendirme}

Eksize edilen lezyonun (Resim 4) histopatolojik incelemesi yapıldı. Kesit yüzü kirli beyaz-sarı renkte ve homojen yapıda olan; $0,7 \mathrm{~cm}$ çapındaki kapsüllü biyopsi materyalinin tümü incelendi. Histolojik olarak; matür, atrofik çok katlı yassı epitel altında ince fibröz kapsül ile çevrili adipo doku ve prolifere olan fibroblastlar ile kalın kollajen lif demetleri izlendi (Resim 4). İmmünohistokimyasal incelemede tümör stromasında ki-67 pozitif hücreler saptandı (Resim 5). Klinik ve histopatolojik bulgulara dayanarak 'fibrolipom' tanısı konuldu.

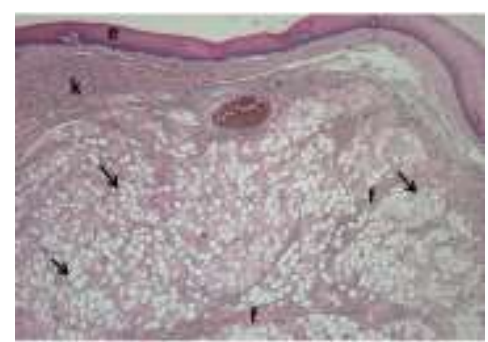

Resim 4. Lezyonun histopatolojik görüntüsü: Oral mukoza epiteli altında (e) fibröz kapsüle sahip(k) birbirlerinden fibröz septalarla(f) ayrılmış matür adiposit topluluklarından (ok) oluşan benign tümör izlenmektedir. (Hematoksilen-Eozin x40)

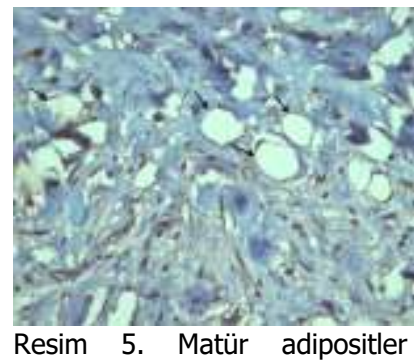

Resim 5. Matür adipositler çevresinde ki-67 pozitif (kahverengi) hücreler (DAB x400)

Sütürleri alınan hastaya yara iyileşmesini takip etmek için bir hafta sonra tekrar kontrol randevusu (operasyondan iki hafta sonra) verildi. Kontrol rande- 
vusunda yara yerinin iyileştiği izlendi (Resim 6). Üc aylık aralıklarla hasta takibe alındı ve ilk üç ayda hastanın asemptomatik olduğu belirlendi.

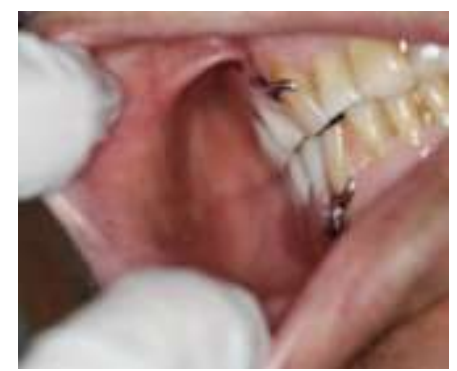

Resim 6. Operasyondan iki hafta sonra yara yerinin iyileşmesi

\section{TARTIŞMA}

Fibrolipomlar, Dünya Sağlık Örgütü tarafından lipomların bir varyantı olarak sınıflandırılır, oral ve maksillofasiyal bölgede nadiren izlenir ${ }^{12}$. Fibrolipom, yağ dokusunun lobülleri ve fibröz bir bileşen ile karakterize, lipomun histolojik bir varyantıdır. Tümörün kıvamı tümörün derinliğine, fibröz dokunun miktar ve dağılımına bağlı olarak yumuşaktan serte değişkenlik gösterebilir ${ }^{6-14}$.

Fibrolipomlarla ilgili İngilizce literatür incelendiğinde; lipomların değerlendirildiği çalışmalar, vaka serileri $^{1-3,7-11,13,15-19}$ ve vaka raporlarının ${ }^{20-69}$ bulunduğu makalelere rastlanmaktadır (Tablo 1). Bilgimiz dahilinde; vaka serileri ve vaka raporları dahil olmak üzere literatürde toplam 241 fibrolipom vakası mevcuttur (Tablo 1). Lipomların değerlendirildiği vaka serilerinde fibrolipom görülme sıklığının \%1.6 ile 50 arasında değiştiği görülmektedir ${ }^{15,16}$ (Tablo 1). Çalışmalarda izlenen farklııklar ırksal özellik, coğrafik karakteristik veya farklı tanı kriterlerine bağı olabilir².

Tablo 1. Fibrolipom vaka sunum ve seri özetleri

\begin{tabular}{|c|c|c|c|c|c|c|}
\hline Yazar ve yayın yılı & $\begin{array}{c}\text { Lezyon } \\
\text { lokalizasyonu }\end{array}$ & \begin{tabular}{|c|} 
Lezyon \\
adedi
\end{tabular} & \begin{tabular}{|l|} 
Cinsiyet \\
K: Kadın \\
E: Erkek
\end{tabular} & $\begin{array}{l}\text { Lezyon } \\
\text { çapı } \\
(\mathrm{cm})\end{array}$ & Yaş & \begin{tabular}{|} 
Lezyon \\
süresi \\
(ay)
\end{tabular} \\
\hline Freidel ve ark. $1947^{20}$ & Ağız Tabanı & & $\mathrm{K}$ & 4,5 & 51 & \\
\hline Carlier $1948^{21}$ & Dil & & $\mathrm{K}$ & \begin{tabular}{|c} 
Findik \\
büyüklüğünde
\end{tabular} & 49 & \\
\hline Pavlovsky $1948^{22}$ & Bukkal Mukoza & & & & & \\
\hline Grether ve ark. $1949^{23}$ & Dişeti & & $\mathrm{K}$ & $\begin{array}{c}\text { Badem } \\
\text { büyüklüğünde }\end{array}$ & 56 & 12 \\
\hline Bruce ve ark. $1954^{24}$ & Bukkal Mukoza & & $E$ & & 43 & 252 \\
\hline Bruce ve ark. 1954 & Dişeti & & $\mathrm{E}$ & & 44 & 36 \\
\hline Dubecq ve ark. $1954^{25}$ & Bukkal Mukoza & & $\mathrm{K}$ & & 50 & 84 \\
\hline Duranti $1956^{26}$ & Ağız Tabanı & & $\mathrm{K}$ & 2 & 30 & 3 \\
\hline Cervellera ve ark. $1957^{27}$ & Yumuşak Damak & & $\mathrm{K}$ & \begin{tabular}{|c|}
$\begin{array}{c}\text { Mandalina } \\
\text { büyüklügünde }\end{array}$ \\
\end{tabular} & 54 & \\
\hline Walters ve ark. $1957^{28}$ & Bukkal S & & $\mathrm{K}$ & \begin{tabular}{|c|} 
Yumurta \\
büyüklüğünde
\end{tabular} & 59 & 60 \\
\hline Newman CW 195729 & Mandibula & & & & & \\
\hline Masdea ve ark. $1958^{30}$ & Dil & & $\mathrm{K}$ & \begin{tabular}{|c|}
$\begin{array}{c}\text { Findik } \\
\text { büyüklügünde }\end{array}$ \\
\end{tabular} & 71 & 72 \\
\hline
\end{tabular}

\begin{tabular}{|c|c|c|c|c|c|c|}
\hline Vazirani ve ark. $1958^{31}$ & Bukkal Mukoza & & $\mathrm{K}$ & 2 & 42 & 240 \\
\hline Rosapepe ve ark. $1958^{32}$ & Bukkal Mukoza & & & & & \\
\hline \begin{tabular}{|l|} 
Rosapepe ve ark. 1958 \\
\end{tabular} & Bukkal Mukoza & & & & & \\
\hline \multicolumn{7}{|l|}{ Rosapepe ve ark. 1958} \\
\hline \multicolumn{7}{|l|}{\begin{tabular}{|l|} 
Rosapepe ve ark. 1958 \\
\end{tabular}} \\
\hline Blake ve ark. $1959^{33}$ & Ağız Tabanı & & $\mathrm{K}$ & 1,5 & 50 & 6 \\
\hline Möbius $1960^{34}$ & Sert Damak & & & \begin{tabular}{|c|} 
Erik \\
büyükü̈ünde \\
\end{tabular} & & \\
\hline Möbius 1960 & Sert Damak & & & \begin{tabular}{c|c|} 
Kiraz \\
büyüklüğunde \\
\end{tabular} & & \\
\hline Möbius 1960 & Ağız Tabanı & & & \begin{tabular}{|c|} 
Erik \\
büyükü̈üunde \\
\end{tabular} & & \\
\hline Sarlis $1960^{35}$ & Dil & & $\mathrm{E}$ & 4,5 & & \\
\hline Gray $1961^{36}$ & Bukkal Mukoza & & $\mathrm{E}$ & 1,8 & 56 & 180 \\
\hline Orlian $1961^{37}$ & Dudak & & $\mathrm{E}$ & 2 & 65 & 216 \\
\hline Anand ve ark. $1962^{38}$ & Bukkal Mukoza & & $\mathrm{E}$ & 5,7 & 15 & 5 \\
\hline Sundberg ve ark. $1962^{39}$ & Bukkal Mukoza & & $\bar{E}$ & $\begin{array}{l}\text { cocuk yumruüü } \\
\text { büyüklü̈ünde }\end{array}$ & 77 & 240 \\
\hline Toto ve ark. $1962^{40}$ & Bukkal Mukoza & & $\mathrm{K}$ & 2,6 & 38 & \\
\hline Colombo ve ark. $1963^{41}$ & Bukkal Mukoza & & $\mathrm{E}$ & \begin{tabular}{|c|} 
Mandalina \\
büyüklü̈̆unde
\end{tabular} & 16 & 12 \\
\hline Emelyaneko $1963^{42}$ & Ağız Tabanı & & $\mathrm{K}$ & 3,5 & 49 & 1 \\
\hline Wehrle ve ark. $1965^{43}$ & Dil & & $\mathrm{E}$ & 0,5 & 67 & \\
\hline Hatziotis ve ark. $1966^{7}$ & Yumuşak Damak & & $\mathrm{K}$ & $\begin{array}{c}\text { Küçük ceviz } \\
\text { büyükügüünde }\end{array}$ & 55 & 1 \\
\hline MacGregor ve ark. $1966^{11}$ & Ağız Tabanı & & $\mathrm{K}$ & & 58 & \\
\hline MacGregor ve ark. 1966 & Bukkal Sulkus & & $\mathrm{K}$ & & 58 & \\
\hline MacGregor ve ark. 1966 & Dişeti & & $\mathrm{E}$ & & 55 & \\
\hline MacGregor ve ark. 1966 & Alt Dudak & & $\mathrm{K}$ & & 68 & \\
\hline MacGregor ve ark. 1966 & Bukkal Sulkus & & $\mathrm{E}$ & & 57 & \\
\hline Borello ve ark. $1967^{44}$ & Bukkal Mukoza & & & & & \\
\hline Panders ve ark. $1967^{45}$ & Bukkal Mukoza & & $\mathrm{K}$ & & 71 & \\
\hline Panders ve ark. 1967 & $\begin{array}{c}\text { Bukkal Mukoza - } \\
\text { Sulkus }\end{array}$ & & $\mathrm{K}$ & & 61 & 18 \\
\hline Panders ve ark. 1967 & $\begin{array}{c}\text { Bukkal Mukoza - } \\
\text { Sulkus }\end{array}$ & & $\mathrm{K}$ & & 66 & 84 \\
\hline Panders ve ark. 1967 & Bukkal Sulkus & & $\mathrm{E}$ & & 60 & 120 \\
\hline Panders ve ark. 1967 & Ağız Tabanı & & $\mathrm{K}$ & & 53 & 18 \\
\hline Panders ve ark. 1967 & Bukkal Mukoza & & $E$ & & 49 & 36 \\
\hline Haag ve ark. $1967^{46}$ & Ağız Tabanı & & $\mathrm{K}$ & 2 & 76 & 12 \\
\hline Haag ve ark. 1967 & Dişeti & & $\mathrm{E}$ & 1 & 69 & \\
\hline Rose $1967^{47}$ & Bukkal Mukoza & & $\mathrm{E}$ & 1,4 & 70 & 96 \\
\hline Stasinopoulos $1967^{48}$ & Sert Damak & & & $\mathrm{x}$ & 63 & \\
\hline Seldin ve ark. $1967^{19}$ & & 2 & & & & \\
\hline Greer ve ark. $1973^{16}$ & Retromolar Bölge & 4 & & & & \\
\hline Greer ve ark. 1973 & Ağız Tabanı & 2 & & & & \\
\hline Greer ve ark. 1973 & Peritonsiller Bölge & 1 & & & & \\
\hline Greer ve ark. 1973 & $\begin{array}{c}\text { Damak (Hamular } \\
\text { çentik) }\end{array}$ & 1 & & & & \\
\hline Visscher ve ark. $1982^{1}$ & Bukkal Sulkus & & $\mathrm{E}$ & 1 & 45 & 48 \\
\hline Visscher ve ark. 1982 & Ağız Tabanı & & $\mathrm{K}$ & 3 & 75 & 6 \\
\hline Visscher ve ark. 1982 & Bukkal Sulkus & & $\mathrm{E}$ & 0,5 & 43 & 0.25 \\
\hline Visscher ve ark. 1982 & Dil & & $\mathrm{K}$ & 1 & 11 & 24 \\
\hline Visscher ve ark. 1982 & Retromolar Bölge & & $\mathrm{K}$ & 1,5 & 68 & 7 \\
\hline Visscher ve ark. 1982 & Bukkal Sulkus & & $\mathrm{K}$ & 2,5 & 57 & 6 \\
\hline Visscher ve ark. 1982 & Dil & & $\mathrm{E}$ & 2 & 41 & 360 \\
\hline Visscher ve ark. 1982 & Üst Dudak & & $\mathrm{E}$ & 1 & 63 & 12 \\
\hline Saitoh ve ark. $1995^{49}$ & Parotis & & $\mathrm{K}$ & 3 & 3 & \\
\hline Dattilo ve ark. $1996^{50}$ & Dil, Sublingual & & $\mathrm{E}$ & & 45 & 120 \\
\hline $\begin{array}{c}\text { Epivantianos ve ark. } 2000 \\
3\end{array}$ & Bukkal Mukoza & & $\mathrm{E}$ & 1 & 40 & \\
\hline Epivantianos ve ark. 2000 & Ağız Tabanı & & $\mathrm{K}$ & 0,5 & 63 & \\
\hline $\begin{array}{c}\text { Said-Al-Naief ve ark. } 2001 \\
8\end{array}$ & Bukkal Mukoza & 22 & & & & \\
\hline Baid-Al-Naief ve ark. 2001 & Bukkal Sulkus & 3 & & & & \\
\hline aaid-Al-Naief ve ark. 2001 & Ağız Tabanı & 3 & & & & \\
\hline baid-Al-Naief ve ark. 2001 & Dil & 3 & & & & \\
\hline Baid-Al-Naief ve ark. 2001 & Alt Dudak & 7 & & & & \\
\hline baid-Al-Naief ve ark. 2001 & Üst Dudak & 1 & & & & \\
\hline Said-Al-Naief ve ark. 2001 & Sert Damak & 2 & & & & \\
\hline baid-Al-Naief ve ark. 2001 & Yumuşak Damak & 2 & & & & \\
\hline Said-Al-Naief ve ark. 2001 & Retromolar Bölge & 3 & & & & \\
\hline baid-Al-Naief ve ark. 2001 & $\begin{array}{c}\text { Pterigomandibular } \\
\text { Rafhe }\end{array}$ & 4 & & & & \\
\hline Fregnani ve ark. $2003^{2}$ & Bukkal Mukoza & 10 & & & & \\
\hline Fregnani ve ark. 2003 & Dil & 1 & & & & \\
\hline Fregnani ve ark. 2003 & Dudak & 2 & & & & \\
\hline Fregnani ve ark. 2003 & Ağız Tabanı & 2 & & & & \\
\hline
\end{tabular}




\begin{tabular}{|c|c|c|c|c|c|c|}
\hline Fregnani ve ark. 2003 & Bukkal Sulkus & 2 & & & & \\
\hline Fregnani ve ark. 2003 & Retromolar Alan & 1 & & & & \\
\hline urlong MA ve ark. $2004^{15}$ & Parotis & 1 & & & & \\
\hline Furlong MA ve ark. 2004 & Bukkal Mukoza & 1 & & & & \\
\hline Biswas ve ark. $2004^{51}$ & Bukkal Mukoza & & $\mathrm{K}$ & 5 & 50 & 12 \\
\hline$\underset{52}{\text { Bandeca MC ve ark. } 2007}$ & Alt Dudak & & $\mathrm{E}$ & 1,5 & 42 & 60 \\
\hline 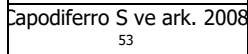 & Alt Dudak & & $E$ & & 43 & 8 \\
\hline Durmuşlar ve ark. $2008^{54}$ & Bukkal Mukoza & & $\mathrm{K}$ & 3 & 42 & 60 \\
\hline $\begin{array}{l}\text { Kumaraswamy ve ark. } \\
2009^{55}\end{array}$ & Bukkal Mukoza & & $\mathrm{K}$ & 1,5 & 48 & 3 \\
\hline $\begin{array}{c}\text { Kumaraswamy ve ark. } \\
2009\end{array}$ & Bukkal Mukoza & & $\mathrm{E}$ & 0,5 & 30 & 24 \\
\hline $\begin{array}{c}\text { Kumaraswamy ve ark. } \\
2009 \\
\end{array}$ & Damak & & $\mathrm{E}$ & 1,5 & 45 & 0.5 \\
\hline $\begin{array}{c}\text { Kumaraswamy ve ark. } \\
2009\end{array}$ & Bukkal Mukoza & & $\mathrm{E}$ & 2,5 & 60 & 24 \\
\hline De Freitas ve ark. $2009^{5}$ & Bukkal Mukoza & & $\mathrm{K}$ & 0,5 & 61 & \\
\hline De Freitas ve ark. 2009 & Ağız Tabanı & & $\mathrm{K}$ & 0,5 & 78 & \\
\hline De Freitas ve ark. 2009 & Ağız Tabanı & & $\mathrm{K}$ & 2 & 49 & \\
\hline De Freitas ve ark. 2009 & Bukkal Mukoza & & $\mathrm{K}$ & 0,8 & 56 & \\
\hline De Freitas ve ark. 2009 & Bukkal Mukoza & & $\mathrm{K}$ & 1 & 66 & \\
\hline De Freitas ve ark. 2009 & Dil & & $\mathrm{K}$ & 2 & 37 & \\
\hline De Freitas ve ark. 2009 & Bukkal Mukoza & & $\mathrm{K}$ & 0,9 & 49 & \\
\hline $\begin{array}{l}\text { Studart-Soares ve ark. } \\
2010^{10}\end{array}$ & Bukkal Mukoza & & K & 1,5 & 53 & 18 \\
\hline $\begin{array}{l}\text { Studart-Soares ve } \\
\text { ark. } 2010\end{array}$ & Dişeti & & $\mathrm{K}$ & 1 & 57 & 2 \\
\hline $\begin{array}{l}\text { Studart-Soares ve } \\
\text { ark. } 2010\end{array}$ & Bukkal Mukoza & & K & 1 & 45 & 2 \\
\hline $\begin{array}{l}\text { Studart-Soares ve } \\
\text { ark. } 2010\end{array}$ & Bukkal Mukoza & & $\mathrm{E}$ & 2 & 42 & 48 \\
\hline Juliasse ve ark.2010 ${ }^{9}$ & Bukkal Mukoza & 9 & & & & \\
\hline Juliasse ve ark. 2010 & Bukkal Sulkus & 3 & & & & \\
\hline Juliasse ve ark. 2010 & Dil & 1 & & & & \\
\hline Juliasse ve ark. 2010 & Retromolar Bölge & 1 & & & & \\
\hline $\begin{array}{c}\text { Manjaunatha ve ark. } 2010 \\
6\end{array}$ & Bukkal Mukoza & & $\mathrm{E}$ & 3 & 75 & 120 \\
\hline Manjaunatha ve ark. 2010 & Bukkal Mukoza & & $\mathrm{E}$ & 1 & 55 & 6 \\
\hline Manjaunatha ve ark. 2010 & Yumuşak Damak & & $\mathrm{E}$ & 1,5 & 70 & 6 \\
\hline E. Manor ve ark. $2011^{18}$ & Bukkal Mukoza & 10 & & & & \\
\hline E. Manor ve ark. 2011 & Dil & 3 & & & & \\
\hline E. Manor ve ark. 2011 & Dudak & 2 & & & & \\
\hline E. Manor ve ark. 2011 & Ağız Tabanı & 2 & & & & \\
\hline E. Manor ve ark. 2011 & Vestibül Mukoza & 2 & & & & \\
\hline Taira ve ark. $2012^{56}$ & & 12 & $\mathrm{E}$ & & & \\
\hline Taira ve ark. 2012 & & 19 & $\mathrm{~K}$ & & & \\
\hline Wu ve ark. $2012^{57}$ & Parotis & 5 & & & & \\
\hline $\begin{array}{l}\text { Khubchandani ve ark. } \\
2012^{14}\end{array}$ & Bukkal Mukoza & & $\mathrm{K}$ & 2,5 & 10 & 24 \\
\hline Shi ve ark. $2014^{58}$ & Dil & & $\mathrm{E}$ & & 0,5 & \\
\hline Camacho ve ark. $2014^{59}$ & Dil & & $\mathrm{K}$ & & 49 & \\
\hline Pereira ve ark. $2014^{60}$ & Dişeti & & $\mathrm{K}$ & 0,8 & 35 & 12 \\
\hline Naruse ve ark. $2015^{17}$ & Ağız Tabanı & & $\mathrm{K}$ & 3 & 76 & 72 \\
\hline Naruse ve ark. 2015 & Damak & & $E$ & 1,5 & 70 & 12 \\
\hline Iwase ve ark. $2015^{61}$ & Bukkal Mukoza & & $\mathrm{E}$ & 2 & 71 & 24 \\
\hline Iaconetta ve ark. $2015^{62}$ & Dil & & $\mathrm{K}$ & 4 & 71 & \\
\hline Castellani ve ark. $2015^{63}$ & Mandibula & & $\mathrm{K}$ & & 25 & \\
\hline Rattan KN ve ark. $2016^{64}$ & Parotis & & $\mathrm{E}$ & 3,5 & 11 & 120 \\
\hline Mungul ve ark. $2017^{65}$ & Dil & & $E$ & 3,2 & 85 & 36 \\
\hline Pippi ve ark. $2017^{66}$ & Dişeti & & $\mathrm{E}$ & 0,5 & 65 & 24 \\
\hline Punjabi ve ark. $2017^{67}$ & Alt Dudak & & $\mathrm{K}$ & 2,5 & 20 & 30 \\
\hline Mishra ve ark. $2017^{68}$ & Alt Dudak & & $\mathrm{E}$ & 3 & 30 & 4 \\
\hline Devi AN ve ark. $2017^{69}$ & Retromolar Bölge & & $\mathrm{K}$ & 1,5 & 50 & 12 \\
\hline Muhsin ve ark. 2018 & Bukkal Mukoza & & $\mathrm{E}$ & 0,7 & 74 & 3 \\
\hline
\end{tabular}

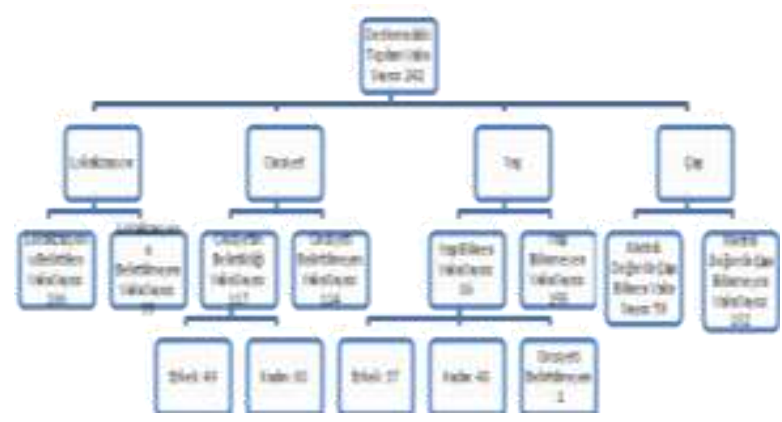

Şema 1. Literatürdeki fibrolipom vakalarının lokalizasyon, cinsiyet, yaş ve boyutlara göre dağııımı

Bazı çalışmalarda fibrolipomların lipomlar gibi ağız içinde en sık bukkal mukozada-7,61 görüldüğü bildirilmektedir. Yapılan literatür incelemesinde de fibrolipomların en çok bukkal mukozada (87 vaka; $\% 41,8)$, izlendiği, bunu sırasıyla ağız tabanı (22 vaka, \%10,5) ve dilin (20 vaka, \%9,6) takip ettiği tespit edildi. Lipomların değerlendirildiği geniş vaka serilerinde fibrolipomların kadınlarda daha fazla görüldüğü bildirilmekle birlikte ${ }^{5,7,10,11}$, eşit sıklıkta olduğunu bildiren çalışmalar da mevcuttur ${ }^{1-3,17}$. Bilgimiz dahilinde, tespit edilen fibrolipom vaka serileri ve vaka raporları dikkate alındığında ise cinsiyet belirtilen 117 vakadan 67'sinin kadın (\%57.26), 50'sinin (\%42,73) erkek olduğu belirlendi. Kadınlarda izlenen fibrolipomların lokalizasyonları en sık sırasıyla bukkal mukoza (16 vaka $\% 32,6)$, ağız tabanı (12 vaka $\% 24,4)$ ve dil (6 vaka $\% 12,2)$ iken, erkeklerde ise sırasıyla bukkal mukoza $(15$ vaka $\% 41,6)$, dil $(6$ vaka $\% 16,6)$ ve dudak (5 vaka $\% 13,8$ ) olduğu görüldü (Tablo 2). Damakta izlenen toplam 13 fibrolipom vakasının beşi sert damak ${ }^{8,34,48}$, beşi yumuşak damak ${ }^{6,-8,27}$, biri hamular çentik ${ }^{16}$, iki vaka için ise sadece damakta izlendiği belirtilmiştir ${ }^{17,55}$. Cinsiyetin belirtildiği çalışmalara göre lokalizasyoncinsiyet dağılımında en dikkat çekici nokta ağız tabanı $1^{5,11,20,33,40}$ ve retromolar ${ }^{69}$ bölgedeki fibrolipomIarın hepsinin kadınlarda bildirilmiş olmasıdır (Tablo 2). 
Tablo 2. Tablo 1'deki fibrolipom vakalarının cinsiyet, yaş, boyut ve süre açısından lokalizasyona göre dağılımı

\begin{tabular}{|c|c|c|c|c|c|c|c|c|}
\hline \begin{tabular}{|c|} 
Lezyon \\
lokalizasyonu
\end{tabular} & \begin{tabular}{|l|} 
Cinsiyeti \\
Belirtil- \\
meyen
\end{tabular} & $\begin{array}{l}\text { Erkek } \\
\text { N (\%) }\end{array}$ & \begin{tabular}{|l|} 
Kadın \\
$\mathrm{N}(\%)$
\end{tabular} & $\begin{array}{l}\text { Toplam } \\
\text { N (\%) }\end{array}$ & \begin{tabular}{|c|} 
Erkek \\
yaş \\
ortala \\
ması
\end{tabular} & $\begin{array}{l}\text { Kadın } \\
\text { yaş } \\
\text { ort. }\end{array}$ & \begin{tabular}{|l|} 
Lezyonu \\
n ort. \\
Çapı \\
(cm)
\end{tabular} & $\begin{array}{l}\text { Ortalam } \\
\text { a lezyon } \\
\text { süresi } \\
\text { (ay) }\end{array}$ \\
\hline Bukkal Mukoza & 56 & $\begin{array}{c}15 \\
(41.6)\end{array}$ & $\begin{array}{c}16 \\
(32.6)\end{array}$ & $\begin{array}{c}87 \\
(41.6)\end{array}$ & 51,5 & 50.5 & 1.9 & 67.2 \\
\hline Bukkal Sulkus & 8 & $\beta(8.3)$ & $4(8.1)$ & $\begin{array}{c}15 \\
(7.2)\end{array}$ & 51.2 & 60.2 & 1.3 & 56 \\
\hline Dil & 8 & $\begin{array}{c}6 \\
(16.6)\end{array}$ & $5(12.2)$ & $\begin{array}{c}20 \\
(9.5)\end{array}$ & 48.3 & 48 & 2.45 & 123 \\
\hline Ağız Tabanı & 10 & - & $\begin{array}{c}12 \\
(24.4)\end{array}$ & $\begin{array}{c}22 \\
(10.5)\end{array}$ & - & 59 & 2.25 & 26.2 \\
\hline $\begin{array}{l}\text { Retromolar } \\
\text { Bölge }\end{array}$ & 9 & - & $2(4)$ & $\begin{array}{c}11 \\
(5.2)\end{array}$ & - & 59 & 1.5 & 9.5 \\
\hline Dişeti & & \begin{tabular}{|c|}
4 \\
$(11.1)$
\end{tabular} & $3(6.1)$ & $7(3.3)$ & 58.25 & 49.3 & 0.82 & 17.2 \\
\hline Dudak & 12 & $\begin{array}{c}5 \\
(13.8) \\
\end{array}$ & $2(4)$ & $19(9)$ & 48.6 & 44 & 2 & 55 \\
\hline \begin{tabular}{|l|} 
Sert Damak \\
\end{tabular} & 5 & - & - & $5(2.3)$ & - & - & - & - \\
\hline $\begin{array}{c}\text { Yumuşak } \\
\text { Damak }\end{array}$ & 2 & (2.6) & $2(4)$ & $5(2.3)$ & $70^{*}$ & 54,5 & $1,5^{*}$ & 3.5 \\
\hline \begin{tabular}{|c|c|}
$\begin{array}{c}\text { Peritonsiller } \\
\text { Bölge }\end{array}$ \\
\end{tabular} & 1 & - & - & $1(0.4)$ & $11^{*}$ & 3* & - & - \\
\hline $\begin{array}{l}\text { terygomandib } \\
\text { ular Rafhe }\end{array}$ & 4 & - & - & 4 (1.9) & - & - & - & - \\
\hline Parotis & 6 & (2.6) & $1(2)$ & $8(3.8)$ & 61.6 & 54.5 & 3.25 & $120 *$ \\
\hline \begin{tabular}{|c|}
$\begin{array}{c}\text { Mandibular } \\
\text { Kemik }\end{array}$ \\
\end{tabular} & 1 & - & $1(2)$ & $2(0.9)$ & - & - & - & - \\
\hline Damak & 1 & $(5.2)$ & - & $3(1.4)$ & 57.5 & - & 1.5 & 6.25 \\
\hline \begin{tabular}{|c|} 
Lokalizasyonu \\
belirtilen
\end{tabular} & $\begin{array}{c}123 \\
\text { (toplam) }\end{array}$ & 37 & 49 & 209 & 51.04 & 51.43 & 1.94 & \\
\hline \begin{tabular}{|l|} 
Lokalizasyonu \\
belirtilmeyen
\end{tabular} & $\begin{array}{c}2 \\
\text { (toplam) }\end{array}$ & 12 & 19 & 33 & & & & \\
\hline $\begin{array}{l}\text { Derlemedeki } \\
\text { vaka sayısı }\end{array}$ & $\begin{array}{c}125 \\
\text { (toplam) }\end{array}$ & 49 & 68 & 242 & & & & \\
\hline
\end{tabular}

Oral lipom ve varyantları her yaş grubunda görülmekle birlikte sıklıkla 40-60 yaş arasında görüldüğg̈ü bildirilmiştir ${ }^{2,15,17,18,61}$. Bilgimiz dahilindeki çalışmalar dikkate alındığında; fibrolipomların çoğunlukla önceki çalışmalarla benzer yaş aralığında görüldüğü (yaş ortalaması $51.4 \pm 17.2$ ) saptandı (Tablo 2).

Yaklaşık 50 yıl önce yayınlanmış bazı literatürlerde lezyon boyutları fındık, ceviz, mandalina gibi nesnelerle ifade edilmişken, metrik değerlerde çapı bildirilen toplam 59 vakadaki en büyük fibrolipom çapı $5.7 \mathrm{~cm}$, en küçük ise $0.5 \mathrm{~cm}$ (ortalama $1.94 \mathrm{~cm}$, erkeklerde ortalama 1.86 , kadınlarda ortalama 2.01 ve standart sapma 1.21) olarak bildirilmiştir (Tablo 1). Bukkal sulkus, retromolar bölge, damak ve dişetinde izlenen fibrolipomların ortalama çapı, diğer fibrolipomların ortalama çapından daha küçük; parotis, dil, ağız tabanı ve dudakta izlenen fibrolipomların ortalama çapının ise diğerlerinden daha büyük olduğu belirlenmiştir (Tablo 2). Mukozanın daha sıkı olduğu bölgelerde daha küçük, kanlanmadan zengin bölgelerde görülen fibrolipomların çapının daha büyük olması dikkat çekici olmakla birlikte, bu konuda ileri çalışmaların yapılması gereklidir.

Literatürde bildirilen hem lipomlar hem de fibrolipom vakalarının histopatolojik olarak çoğunlukla ince bir kapsül içerdiği vurgulanmıştır ${ }^{6}$. Fibrolipomların, bağ doku bantları arasına serpiştirilmiş şekilde olgun yağ dokusu içermesi nedeniyle diğer lipom varyantlarından farklı şekilde proliferatif aktivitesinin daha yüksek olduğu bildirilmiştir ${ }^{53}$. Lipom ve varyantlarının proliferatif aktivitesinin immünohistokimyasal analizlerinin yapıldığı iki çalışmada PCNA ve ki-67 ekspresyonları incelenmiştir ${ }^{2,17}$. Beş lipom varyantı arasından PCNA ve ki-67 ekspresyon değerini en yüksek fibrolipom, en düşük klasik lipomda bildirmesine rağmen ${ }^{2}$, başka bir çalışmada dört lipom varyantı arasında PCNA ekspresyon değerini en düşük fibrolipom, en yüksek intramuskuler lipom, ki-67 ekspresyon değerini en yüksek intramuskuler lipoma, en düşük fibrolipom ve spindle lipom olarak bildirilmiştir ${ }^{17}$. Çalışmalar arasındaki farklı değerler, çalışmanın ${ }^{2}$ birinde 18 , diğerinde ise sadece iki tane ${ }^{17}$ fibrolipom vakası bulunmasından kaynaklanabilir. Artmış PCNA ekpresyonu daha hızlı büyümeyi göstermekle birlikte, cerrahi yaklaşım sonrası takip edilen hiçbir olguda nüks görülmediği belirlenmiştir². Öte yandan, ki-67 ekspresyonu bulunan vakalarda rekürrens veya malign transformasyon olasılığına karşı hastaların uzun süreli takip edilmesi gerektiğini önermektedirler ${ }^{17}$. İncelediğimiz vakada ki-67 pozitif hücrelerin bulunması nedeniyle hasta üçer aylık aralıklarla periyodik takibe alındı.

Lipom ve fibrolipomun etyopatogenezi tam olarak bilinmemektedir. Endokrin dengesizliğine bağlı konjenital lezyon, fibromatöz tümörün dejenerasyonu yoluyla ortaya çıkan veya lipoblastomatoz olgunlaşmasından kaynaklanan ve tekrarlayan hafif travmanın yağ dokusunun çoğalmasını tetikleyebileceği ileri sürülmüştür ${ }^{1-4}$. İncelenen vakada ısırmaya bağlı tekrarlayan travmanın fibrolipoma neden olduğu düşünüldü.

Lipomların konvansiyonel radyografilerde değişiklik gösterebildiği sadece iki vakada bildirilmiştir ${ }^{10,19}$. Manyetik rezonans görüntüleme (MRG) oral lipomatöz lezyonların teşhisinde yararlıdır ${ }^{56,70}$. Lipomlar MRG'de genellikle yüksek sinyal intensitesi gösterir ve hem T1 hem de T2 ağırlıklı görüntülerde iyi kapsüllü kitle olarak izlenirler ${ }^{70,71}$. Özellikle yağ baskılanmış MRG teşhis için faydalı olduğu bildirilmiştir. Öte yandan, fibrolipomlar MRG'de lipomlardan daha heterojen olmakla birlikte, bol miktarda kollajen lifleri içeren vakalarda fibroma benzeri düşük sinyal intensitesi gösterebilirler ${ }^{61}$. Lipomların yağ içermeyen komponentleri sinyal yoğunluğunda azalmaya neden olur ${ }^{70}$. İncelediğimiz vakada fibrolipomun panoramik radyografide bulgu verdiği görüldü. Lezyonun küçük boyutlarda ve semptomsuz olmasından dolayı herhangi bir ileri görüntüleme tekniğine gerek duyulmadı. 
Lipomlar esas olarak cerrahi eksizyonla tedavi edilir. 2017'de yayınlanan iki literatürde ${ }^{68,69}$ fibrolipomun eksizyonunda diode lazer kullanıldığı bildirilmiştir. Lipomun prognozu genel olarak iyidir ve ameliyat uygun şekilde planlandığında rekürrens olası değildir. Bununla birlikte, bukkal mukozadaki bir lipom vakasının liposarkoma dönüştüğü bildirilmiştir ${ }^{72}$.

\section{SONUÇ}

Fibrolipomlar klasik lipoma kıyasla artmış büyüme potansiyeline sahip olması, herhangi bir sendroma bağıı olmaması ve düşük rekürrens oranı ile ayrı bir klinik-patolojik varlığı temsil eder. Oral patologlar tarafından sağlanan mikroskopik / histolojik bulgular, doğru teşhis için klinik özellikler ile kombine edilmelidir. Doğru tanı için oral patolog ile konsültasyon ve eksize edilen dokunun histopatolojik incelemesi başarılı tedavinin sağlanmasında ve malign transformasyonun önlenmesinde önemli bir role sahiptir. $\mathrm{Bu}$ nedenle histopatolojik olarak ki-67 değeri incelenip, pozitif olduğu durumlarda hasta mutlaka takibe alınmalıdr.

NOT: Calışmada herhangi bir yazar, kurum ya da kuruluş ile çıkar çatışması içerisinde bulunmamaktadır. Makale daha önce hiçbir yerde yayınlanmamış ve yayınlanmak üzere işlem görmemektedir

\section{KAYNAKLAR}

1- de Visscher JG. Lipomas and fibrolipomas of the oral cavity. J Oral Maxillofac Surg 1982; 10:17781.

2- Fregnani ER, Pires FR, Falzoni R, Lopes MA, Vargas $P A$. Lipomas of the oral Lipomas of the oral cavity: clinical findings, histological classification and proliferative activity of 46 cases. Int J Oral Maxillofac Surg 2003; 32:49-53.

3- Epivatianos A, Markopoulos AK, Papanayotou P. Benign tumors of adipose tissue of the oral cavity: a clinicopathologic study of 13 cases. J Oral Maxillofac Surg 2000; 58:1113-7.

4- R. L. Kiehl. Oral fibrolipoma beneath complete mandibular denture. J Am Dent Assoc 1980; 100:561-2.

5- deFreitas MA, Freitas VS, de Lima AA, Pereira FB Jr, dos Santos JN. Intraoral lipomas: a study of 26 cases in a Brazilian population. Quintessence Int 2009; 40: 79-85.
6- Manjunatha BS, Pateel GS, Shah V. Oral fibrolipoma-a rare histological entity: report of 3 cases and review of literature. J Dent 2010; 7:226-31.

7- Hatziotis JC. Lipoma of the oral cavity. Oral Surg Oral Med Oral Pathol 1971; 31:511-24.

8- Said-Al-Naief N, Zahurullah FR, Sciubba JJ. Oral spindle cell lipoma. Ann Diagn Pathol 2001; 5:20715.

9- Juliasse LE, Nonaka CF, Pinto LP, Freitas Rde A, Miguel MC. Lipomas of the oral cavity: clinical and histopathologic study of 41 cases in a Brazilian population. Eur Arch Otorhinolaryngol. 2010; 267:459-65.

10-Studart-Soares EC, Costa FW, Sousa FB, Alves AP, Osterne RL. Orallipomas in a Brazilianpopulation: A 10-year study and analysis of 450 cases reported in the literature. Med Oral Patol Oral Cir Bucal 2010; 15:e691-6.

11-MacGregor AJ, Dyson DP. Oral lipoma. A review of the literature and report of twelve new cases. Oral Surg Oral Med Oral Pathol 1966; 21:770-7.

12-Ertaş Ü, Sarvan A, Dayı E, Gürbüz G. Nadir Boyutlarda Görülen Bir Yanak Bölgesi Lipomu. Atatürk Üniv Diş Hek Fak Derg 1999; 2:72-74

13-Nielsen GP, Mandahl N. Adipocytic tumors. In: Fletcher CDM, Unni K, Mertens F (eds). World HealtH Organization Histological Classification of Tumors. Pathology and Genetics Tumours of Soft Tissue and Bone. IARC Press: Lyon, 2002; 19-46

14-Khubchandani M, Thosar NR, Bahadure RN, Baliga MS, and Gaikwad RN. Fibrolipoma of buccal mucosa. Contemp Clin Dent 2012; 3:S112-4.

15-Furlong MA, Fanburg-Smith JC, Childers EL. Lipoma of the oral and maxillofacial region: site and subclassification of 125 cases. Oral Surg Oral Med Oral Pathol Oral Radiol Endod 2004; 98:44150.

16-Greer RO, Richardson JF. The nature of lipomas and their significance in the oral cavity. A review and report of cases. Oral Surg Oral Med Oral Pathol 1973; 36:551-7.

17-Naruse T, Yanamoto S, Yamada S.-I. et al. Lipomas of the oral cavity: clinicopathological and immunohistochemical study of 24 cases and review of the literature. Indian J Otolaryngol and Head Neck Surg 2015; 67:67-73.

18-Manor E, Sion-Vardy N, Joshua BZ, Bodner L. Oral lipoma: analysis of 58 new cases and review of the literature. Ann Diagn Pathol 2011; 15:257-61. 
19-Seldin HM, Seldin SD, Rankower W, Jarrett WJ. Lipomas of the oral cavity: report of 26 cases. J Oral Surg 1967; 25:270-4.

20-Freidel Ch., Lair J, and Permod. Lipom edu plancher de la bouche, Rev Stomat 1947; 48: 425-7.

21-Carlier G. Lipome de la langue, Rev Stomat 1948; 49: 36-42.

22-Pavlovsky AS. Lipofibroma de la bolla grassosa de Bichat, Bol. Trab. Soc. Argent. 1948; Cir. 10: 196.

23-Grether A, and Tetu J. Un cas de lipome de la gencive, Rev Stomat 1949; 50: 206-210.

24-Bruce KW, and Royer RQ. Lipoma of the Oral Cavit; Report of Three Cases. Oral Surg 1954; 7: 930-8.

25-Dubecq and Decamps: Manifestation endobuccale d'un fibrolipome ayant pour point de depart la boule grasseuse de Bichart. Rev Franc Odontostomat 1955; 2: 389.

26-Duranti E. Su un caso di fibrolipoma del pavimento della bocca, Boll. Mal. Orecch 1956; 74: 269-272.

27-Cervellera G. and Pennetta G. Fibrolipoma del palato molle. Minerva Otorinolaring 1957; 7: 38791.

28-Walters TH. and Steiner M. Fibrolipoma of Oral Cavity: Report of a Case. Harlem Hosp Bull 1957; 10: 46-52.

29-Newman CW. Fibrolipoma of the Mandible: Report of a Case. J. Oral Surg 1957; 15: 251.

30-Masdea E. and Pace G. I lipomi della lingua,Gazz. Int. Med. Chir. 1958; 63: 1205-13.

31-Vazirani SJ. and De Vore DT. Fibrolipoma of the Oral Cavity; Report of a Case. Oral Surg 1958; 11: 355-8.

32-Rosapepe, M. and Faraone V. Il Fibrolipoma del cavo orale, Ann Stomat 1958; 7: 881-886.

33-Blake H. and Blake F.S. Lipoma in the Floor of the Mouth; Report of a Case. Oral Surg 1959; 12: 1436-8.

34-Möbius W. Über lipome in Mundhöhlenbereich, Zahnaerztl. Welt 1960; 61: 267-2711.

35-Sarlis, B. G.: Two Cases of Lipoma of the Right Half of the Tongue, Acta Stomat. Hellen. 1960; 4: 255-265.

36-Gray, W.: Oral Lipoma: Report of Two Cases, Brit Dent J 1961; 110: 55-6.

37-Orlian, A. J.: Lipomas of the Tongue, New York Dent J 1961; 27: 337-8.
38-Anand, S. C., and Khorana, M. M.: Lipoma of Oral Buccal Vestible, J. All-India Dent. Ass. 1962; 34 : 296-7, 308.

39-Sundberg, S., and Ljungberg, U.: Fibrolipom i buccan av ovanling storlek. Odont T 1962; 70: 457-60.

40-Toto, P. D., and Choukas, N.: Fibrolipoma of the Buccal Mucosa, Oral Surg. 1962; 15: 1423-1425.

41-Colombo, E., and Tosi, C.: Sui lipomi del corpo adiposo di Bichat, Arch Ital Otol 1963; 74: 733-45.

42-Emelyanenko V.: A Rare Case of Lipoma Localization, Stomatologiia (Moskva) 1963; 42: 789.

43-Wehrle, D. P.i Emmings, F. G., and Koepf, S. W.: Lipoma of the Oral Cavity; Report of Four Cases, Oral Surg. 1965; 20: 138-40.

44-Borello, E. D., Poex A., and Oviedo R.: Lipoma and Fibrolipoma; Revision of the Literature and Report of Two Cases, Rev. Asoc. Odont. Argent. 1967; 55: 130-4.

45-Panders, A. K., and Scherpenisse, L. A.: Oral Lipoma, Brit. J. Oral. Surg. 1967; 5: 33-41.

46-Haag, R. Nicolas, P., and Frank, R. M.: Contributions a l'etude du fibrolipome de la cavite buccale, Rev Franc Odontostomat 1967; 14: 162940,

47-Rose, H. P.: Fibrolipoma of the Oral Cavity: Report a Case, New York Dent. J. 1967; 33: 603-605,

48-Stasinopoulos, E.: Lipomas of the Oral Cavity; a Clinical and Histological Study With Report a Case, Acta Stomat. Hellen. 1967; 11: 259-261, 335-57.

49-Saitoh Y, Hama T, Ishizaka S, Kawaguchi M, Terazono $T$, Hyuga $M$, et al. Fibrolipoma of the parotid in a child. Am J Otolaryngol 1995; 16:4335

50-Datillo DJ, Ige JT, Nwana EJ. Intraoral lipoma of the tongue ad submandibular space: report of a case. J Oral Maxillofac Surg 1996; 54:915-7

51-Biswas S, Kundu IN. Giant fibrolipoma of the oral cavity. Indian J Otolaryngol Head Neck Surg 2004; 56:118-9.

52-Bandeca MC, Padua JM, Nadalin MR, et al. Oral soft tissue lipomas: a case series. J Can Dent Assoc 2007; 73:431-4.

53-Capodiferro S, Maiorano E, Scarpelli F, et al: Fibrolipoma of the lip treated by diode laser surgery: a case report. J Med Case Reports 2008; 2:301. 
54-Durmuşlar, C., Peker, İ., Gültekin, S.E. Yanak mukozasında gelişen bir fibrolipom olgusu. Türk Oral ve Maksillofasiyal Cerrahi Derneği 15. Uluslararası Kongresi, Antalya, Türkiye. PP031

55-Kumaraswamy S, Madan, Keerthi R, ShaktiS. Lipomas of oralcavity: case reports with review of literature. J Maxillofac Oral Surg 2009; 8:394-7.

56-Y. Taira, K. Yasukawa, I. Yamamori, and M. Iino. Oral lipoma extending superiorly from mandibular gingivobuccal fold to gingiva: a case report and analysis of 207 patients with oral lipoma in Japan. Odontology 2012; 100:104-8.

57-Wu S, Liu G, Chen R, Guan Y. Role of ultrasound in the assessment of benignity and malignancy of parotid masses. Dentomaxillofac Radiol 2012; 41:131-5.

58-Shi J, Zhang J, Ding M, Cao Q. Lip cleft, bifid tongue and fibrolipoma: a case report of rare congenital anomaly. $\mathrm{Br} \mathrm{J}$ Oral and Maxillofacial Surg 2014; 52:e36-8.

59-Camacho ML, Parra Márquez O, David Peña C, Stea D. Fibrolipoma Lingual: reporte de un caso y revisión de la literatura. Rev Venez Invest Odont IADR 2014; 2:147-55.

60-Pereira T, Shetty S, Sapdhare S, Tamgadge A. Oral fibrolipoma: A rare histological variant. Indian J Dent Res 2014; 25:672-4.

61-Iwase M, Saida N, Tanaka Y. Fibrolipoma of the Buccal Mucosa: A Case Report and Review of the Literature. Case Rep Pathol. 2016; 2016:5060964.

62-Iaconetta G, Friscia M, Cecere A, Romano A, Orabona GDA, Califano L. Rare fibrolipoma of the tongue: A Case Report. J Med Case Rep 2015; 9:177.

63-Castellani A, Bocchialini G, Ferrari L. A rare case of intraosseous fibrolipoma of the mandible: diagnosis and treatment. Case Rep Dent 2015; 2015:519824.

64-Rattan KN, Singh S, Bansal S. Right Parotid Fibrolipoma: A Rare Lesion in a Child. APSP J Case Rep. 2016; 1;7:30.

65-Mungul S, Maharaj S, Masege SD. Lingual Fibrolipoma - A rare clinicopathological entity. S Afr J Surg 2017; 55:36.

66-Pippi R, Santoro M, Patini R. Fibrolipoma of the Oral Cavity: Treatment Choice in a Case with an Unusual Location. J Clin Diagn Res. 2017; 11: ZJ07-8.
67-Punjabi VH, Patel S, Pathak J, Swain N. Fibrolipoma of Lip in a Young Individual: A Rare Presentation. J Contemp Dent 2017; 7:181-4

68-Mishra, R.; Bhasin, N.; Sahu, A.; Ghate, S. Oral Fibrolipoma-: A Rare Presentation Case Report and Review of Literature. JAMMR 2017; 23: 1-5.

69-Devi AN, Sowbhagya MB, Balaji P, Mahesh Kumar TS. An uncommon case of fibrolipoma. Indian J Dent Res 2017; 28: 699-701.

70-L. W. Bancroft, M. J. Kransdorf, J. J. Peterson, and M. I. O'Connor. Benign fatty tumors: classification, clinical course, imaging appearance, and treatment. Skeletal Radiol 2006; 35:719-33.

71-T. Chikui, K. Yonetsu, K. Yoshiura et al. Imaging findings of lipomas in the orofacial region with $\mathrm{CT}$, US, and MRI. Oral Surg Oral Med Oral Pathol Oral Radiol Endod 1997; 84:88-95.

72-Yamada K, Dohara Y, Nagata M, Kawashima K, Yamashita S. A case of liposarcoma of the cheek. Jap J Clin Oncol 1979; 9:123-30.

\author{
Yazışma Adresi \\ Muhsin Said Karataş \\ Gazi Üniversitesi Diş Hekimliği Fakültesi, \\ Ağız, Diş ve Çene Radyolojisi A.D. \\ Ankara \\ e-mail: dt.mskaratas@gmail.com
}

